\title{
Group III Metabotropic Glutamate Receptors Maintain Tonic Inhibition of Excitatory Synaptic Input to Hypocretin/Orexin Neurons
}

\author{
Claudio Acuna-Goycolea, Ying Li, and Anthony N. van den Pol \\ Department of Neurosurgery, Yale University School of Medicine, New Haven, Connecticut 06520
}

Hypocretin/orexin neurons play an important role in hypothalamic arousal. Synaptic glutamate input to hypocretin neurons regulates cell firing. We studied the actions of group III metabotropic glutamate receptors (mGluRs) in modulating the activity of hypocretin neurons using whole-cell voltage- and current-clamp recording in mouse whole hypothalamic slices or minislices consisting only of the lateral hypothalamus. Selective green fluorescent protein expression was used to detect live hypocretin neurons. The mGluR agonist $\mathrm{L}$-(+)-2-amino-4-phosphonobutyric acid (L-AP-4) inhibited synaptic input to hypocretin neurons in a dose-dependent manner; both spontaneous glutamate and GABA-mediated synaptic currents were reduced in frequency. L-AP-4 also reduced the amplitude of postsynaptic potentials evoked by a stimulating electrode placed medial or lateral to the recorded cell. No postsynaptic effect of $\mathrm{L}-\mathrm{AP}-4$ was found relative to membrane potential, input resistance, or AMPA-evoked currents. L-AP-4 appeared to act by a presynaptic mechanism and reduced the frequency of both glutamate- and GABA-mediated miniature events recorded in the presence of tetrodotoxin, with no change in amplitude. (RS)-phosphonopentanoic acid (CPPG), a group III mGluR antagonist, suppressed the actions of L-AP-4. Of substantial interest, CPPG by itself increased synaptic activity recorded in hypocretin neurons, suggesting an ongoing inhibitory tone attributable to activation of group III mGluRs. Glutamatergic interneurons have been suggested to play a role in a positive feedback recruitment of hypocretin on hypocretin neurons. L-AP-4 blocked hypocretin-mediated increases in EPSCs and attenuated the hypocretin-mediated increase in spike frequency. Together, these data suggest that tonically active inhibitory mGluRs are expressed on local hypocretinsensitive glutamate neurons within the lateral hypothalamus that modulate the output of the hypocretin arousal system.

Key words: arousal; feeding; interneuron; neuropeptide; sleep; lateral hypothalamus

\section{Introduction}

Hypocretin/orexin neurons in the hypothalamus play a key role in arousal. Loss of hypocretin in transgenic mice and the absence of a hypocretin receptor in dogs causes narcolepsy (Chemelli et al., 1999; Lin et al., 1999). In parallel, humans with narcolepsy generally have depressed levels of hypocretin in their CSF (Nishino et al., 2000), and postmortem studies of human narcoleptic brains show that the majority of hypocretin cells are absent (Peyron et al., 2000; Thannickal et al., 2000). Hypocretin neurons maintain short axonal projections to the lateral hypothalamus (LH) and long projections to many other regions of the brain, including the locus ceruleus, dorsal raphe, dorsal tegmentum, and tuberomammillary nucleus (Peyron et al., 1998), in which hypocretin exerts excitatory actions (Hagan et al., 1999; Horvath et al., 1999; Eriksson et al., 2001; Burlet et al., 2002; Liu et al., 2002). Hypocretin neurons receive input from large numbers of

Received 0ct. 3, 2003; revised Feb. 10, 2004; accepted Feb. 10, 2004.

This work was supported by National Institutes of Health Grants NS 34887 and NS 41454 and the National Science Foundation (A.N.v.d.P.). C.A.-G. was supported in part by Chilean Conicyt (Beca de Apoyo de Tesis Doctoral) and Mejoramiento de la Calidad y la Equidad de la Educación Superior.

Correspondence should be addressed to Anthony N. van den Pol, Department of Neurosurgery, Yale University Medical School, 333 Cedar Street, New Haven, CT 06520. E-mail: anthony.vandenpo@@yale.edu.

DOI:10.1523/JNEUROSCI.5416-03.2004

Copyright $\odot 2004$ Society for Neuroscience $\quad$ 0270-6474/04/243013-10\$15.00/0 axons that contain neurotransmitter glutamate, indicated by immunoreactivity for the vesicular glutamate transporter vGluT2 (Li et al., 2002). In addition, excitatory synaptic input to the hypocretin neurons is virtually blocked with ionotropic glutamate receptor antagonists, suggesting that the primary excitatory input is glutamate.

Group III metabotropic receptors (mGluRs) have been found in many regions of the brain (Bradley et al., 1998; Evans et al., 2000; Awatramani and Slaughter, 2001; Losonczy et al., 2003; Valenti et al., 2003), including the hypothalamus (Meeker et al., 1994; Ghosh et al., 1997; Schrader and Tasker, 1997; Chen and van den Pol, 1998; van den Pol et al., 1998b) and include mGluR4, mGluR6, mGluR7, and mGluR8. Activation of these mGluRs activates $\mathrm{G}_{\mathrm{i}} / \mathrm{G}_{\mathrm{o}}$-proteins, causing a decrease in cAMP, and modulates synaptic activity by altering phosphorylation of ion channels, receptors, and second-messenger systems (Nakanishi, 1994; Cartmell and Schoepp, 2000; Schoepp, 2001). Group III mGluRs have been localized immunocytochemically to presynaptic axons in some brain regions and to postsynaptic cells in other brain regions (Bradley et al., 1996, 1999; Shigemoto et al., 1997). In some brain areas, group III mGluRs selectively inhibit excitatory synaptic activity (Awad-Granko et al., 2001). In other regions of the brain, activation of group III mGluRs has been reported to inhibit selectively GABAergic neurons, and this disinhibition led 
to an increase in circuit activity (Semyanov and Kullmann, 2000). Group III mGluRs have also been reported to enhance directly glutamate release in layer 5 of the cortex (Evans et al., 2000) or to attenuate glutamate responses by a direct postsynaptic mechanism in the nucleus accumbens (Taverna and Pennartz, 2003).

Because previous studies have not examined the presence or actions of metabotropic glutamate receptors in the hypothalamic arousal system, we asked whether group III mGluRs would modulate the activity of hypocretin cells or the excitatory or inhibitory synaptic input to these neurons using whole-cell voltage- and current-clamp recording in mouse hypothalamic slices. Hypocretin neurons that are scattered in the lateral hypothalamus/ perifornical area were identified by the selective expression of green fluorescent protein (GFP) under control of the hypocretin promoter (Li et al., 2002; Yamanaka et al., 2003). We found that activation of mGluRs had a substantial effect on both the synaptic input to hypocretin neurons and on the discharge rate of these cells. Blocking group III mGluRs with antagonists revealed an ongoing tonic presynaptic inhibition.

\section{Materials and Methods}

Hypothalamic slices. Hypothalamic slices were prepared from transgenic mice (from Dr. T. Sakurai, University of Tsukuba, Japan) in which the hypocretin promoter drove GFP expression selectively in immunocytochemically identified hypocretin neurons, as described previously (Li et al., 2002; Yamanaka et al., 2003). Briefly, 2- to 3.5-week-old animals maintained in a $12 \mathrm{hr}$ light/dark cycle, were deeply anesthetized (sodium pentobarbital, $100 \mathrm{mg} / \mathrm{kg}$ ) during the light part of the cycle (lights on at 6:00 A.M.; animals were used between 11:00 A.M. and 4:00 P.M.), and then the brain was rapidly removed and placed in ice-cold oxygenated ( $95 \% \mathrm{O}_{2}-5 \% \mathrm{CO}_{2}$ ) solution containing the following (in $\mathrm{mM}$ ): 220 sucrose, $2.5 \mathrm{KCl}, 6 \mathrm{MgCl}_{2}, 1 \mathrm{CaCl}_{2}, 1.25 \mathrm{NaH}_{2} \mathrm{PO}_{4}, 26 \mathrm{NaHCO}_{3}$, and 10 glucose, $\mathrm{pH} 7.4$ with $\mathrm{NaOH}$. A block of tissue containing the hypothalamus was dissected, and coronal slices $(200-300 \mu \mathrm{m})$ were cut in sucroseartificial CSF (ACSF) with a vibratome. In some experiments, the medial hypothalamus was cut off from the fornix medially, leaving a slice that consisted only of the LH. After $2 \mathrm{hr}$ of recovery from sectioning, slices were moved to a recording chamber mounted on an Olympus Optical (Tokyo, Japan) BX51WI upright microscope equipped with videoenhanced infrared-differential interference contrast (DIC) and fluorescence. Tissue was superfused with gassed ACSF $\left(95 \% \mathrm{O}_{2}-5 \% \mathrm{CO}_{2}\right)$ that contained the following (in mM): $124 \mathrm{NaCl}, 3 \mathrm{KCl}, 2 \mathrm{MgCl}_{2}, 2 \mathrm{CaCl}_{2}, 1.23$ $\mathrm{NaH}_{2} \mathrm{PO}_{4}, 26 \mathrm{NaHCO}_{3}$, and 10 glucose, $\mathrm{pH} 7.4$ with $\mathrm{NaOH}$. The solution was preheated to $33^{\circ} \mathrm{C}$ before entering the chamber. Neurons were visualized with an Olympus Optical $40 \times$ water-immersion lens.

All experimental procedures involving animals were approved by the Yale University Committee on Animal Care and Use.

Electrophysiology. Whole-cell current- and voltage-clamp recordings were performed using low-resistance patch pipettes (4-6 M $\Omega$ ) made from borosilicate glass tubing (World Precision Instruments, Sarasota, FL) using a PP-83 vertical puller (Narishige, Tokyo, Japan). Recording pipettes were filled with a pipette solution containing the following (in mM): $145 \mathrm{KMeSO}_{4}$ (or $\mathrm{KCl}$ for IPSCs), $1 \mathrm{MgCl}_{2}, 10 \mathrm{HEPES}, 1.1 \mathrm{EGTA}, 2$ $\mathrm{Mg}$-ATP, and $0.5 \mathrm{Na}_{2}$-GTP, pH 7.3 with $\mathrm{KOH}$. Hypocretin neurons under direct visual observation of GFP fluorescence and DIC were recorded. The whole-cell configuration was obtained after gentle application of negative pressure, and capacitance was compensated automatically using Pulse software (HEKA Elektronik, Lambrecht/Pfalz, Germany). Input resistance was continuously monitored, and only those cells with stable access resistance (changes $<10 \%$ ) were used for analysis. Some neurons were filled with tracers in the pipette to verify that GFPexpressing hypocretin cells were recorded. An EPC9 amplifier and Pulse software were used for data acquisition (HEKA Elektronik). PulseFit (HEKA Elektronik), Axograph (Axon Instruments, Foster City, CA), and Igor Pro (WaveMetrics, Lake Oswego, OR) software were used for analysis. Statistical analyses were performed using one-way ANOVA for between-groups (i.e., control, treatment, and recovery) comparisons. To detect pairwise differences, we used ANOVA followed by a Bonferroni post hoc test for multiple comparisons. The nonparametric KolmogorovSmirnov test was used for comparison of the cumulative fractions of the amplitude before and after drug applications. $p<0.05$ was considered statistically significant; data are reported as means \pm SEM.

To study evoked potential responses, we used a bipolar electrode (World Precision Instruments) to deliver electrical stimulation (50-100 $\mu \mathrm{A}, 0.2-0.5 \mathrm{msec}, 0.1-0.2 \mathrm{~Hz})$. Excitatory potentials were evoked with the stimulation electrode placed within the lateral hypothalamus, lateral or medial to the recorded cell. In these experiments, $30 \mu \mathrm{M}$ bicuculline (BIC) was bath applied to block inhibitory transmission. The chemical stimulation experiments were made by pressure application (10-20 psi, 5-10 msec) (Picospritzer II; Parker-Hannefin, Fairfield, NJ) of a small microdrop of L-glutamate (5-10 mM) to the surface of the lateral hypothalamus, using a broken patch pipette of 50-100 $\mu \mathrm{m}$ tip diameter, as described previously (Belousov and van den Pol, 1997; Daftary et al., 1998; Smith and Dudek, 2001). These experiments were conducted in a slice preparation in which the lateral hypothalamic area was surgically isolated by cutting away and removing the rest of the tissue. The pipette was positioned such that microapplied glutamate flowed away from the recorded cell to minimize any direct glutamate effect, given by the activation of glutamate receptors located on the soma of the recorded cell. Glutamate microdrops were done in the presence of $30 \mu \mathrm{M}$ BIC to block inhibitory transmission. For measurements of AMPA-evoked currents, 5 or $30 \mu \mathrm{M}$ AMPA was applied for $20 \mathrm{sec}$ to the recorded cell using a low-resistance pipette; these recordings were done holding the cells at $-60 \mathrm{mV}$ and in presence of $0.5 \mu \mathrm{M}$ tetrodotoxin (TTX). Drug applications were delivered by a flow pipe with a large $350 \mu \mathrm{m}$ diameter aimed at the recorded cell.

Reagents. Most of reagents used were purchased from Sigma (St. Louis, $\mathrm{MO}$ ) and included the following: group III metabotropic agonist L-(+)2-amino-4-phosphonobutyric acid (L-AP-4), BIC methiodide (BIC), DL2-amino-5-phosponovaleric acid (AP-5), 6-cyano-7-nitroquinoxaline2,3-dione (CNQX), and AMPA. (RS)-phosphonopentanoic acid (CPPG) was obtained from Tocris Cookson (Ballwin, MO). Hypocretin-2 (Hcrt-2) was synthesized by the Stanford University Peptide Facility. TTX was obtained from Alomone Labs (Jerusalem, Israel).

\section{Results \\ Group III mGluRs modulate excitatory transmission in lateral hypothalamus}

To study the possible modulation of excitatory inputs to hypocretin neurons by group III mGluRs, spontaneous postsynaptic currents (sPSCs) were recorded at $-60 \mathrm{mV}$ holding potential using the whole-cell voltage-clamp configuration in normal recording buffer. Under these conditions, application of L-AP-4 $(100 \mu \mathrm{M})$ reversibly suppressed the frequency of sPSCs by $28.1 \%$ (Fig. $1 A, B$ ) (range, $10.1-51.9 \% ; p<0.05 ; n=7$; ANOVA). The time course of the L-AP-4 response is seen in Figure $1 A$. In the presence of $30 \mu \mathrm{M}$ BIC to block inhibitory synaptic responses, L-AP-4 $(100 \mu \mathrm{M})$ reduced by $37 \%$ the frequency of EPSCs (range, 16.1-56.4\%; $p<0.01 ; n=6$; ANOVA) (Fig. $1 D$ ). This effect was dose dependent (Fig. 1C).

Pretreatment with $200 \mu \mathrm{M} \mathrm{CPPG}$, an antagonist of group III mGluRs (Toms et al., 1996; Evans et al., 2000; Awatramani and Slaughter, 2001), significantly attenuated the effects of L-AP-4 $(50 \mu \mathrm{M})$, consistent with the mediation by group III mGluRs $(p<0.01 ; n=6$; ANOVA followed by a Bonferroni procedure for multiple comparisons) (Fig. 1D). When $50 \mu \mathrm{M} \mathrm{AP-5}$ and 10 $\mu \mathrm{M}$ CNQX were added to the bath, EPSCs were completely blocked, indicating that glutamate was the transmitter responsible for excitatory currents in these hypocretin neurons $(n=5$; data not shown). These results support the view that group III mGluRs modulate the excitatory synaptic inputs to hypocretin cells.

To further test the effect of L-AP-4 on glutamate synaptic 
A
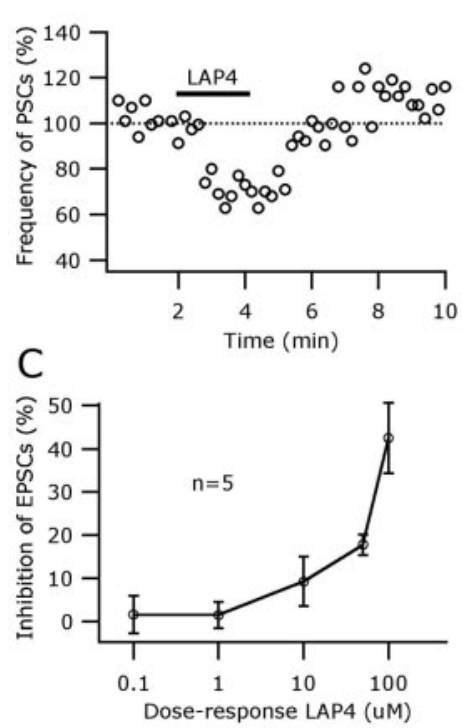

B
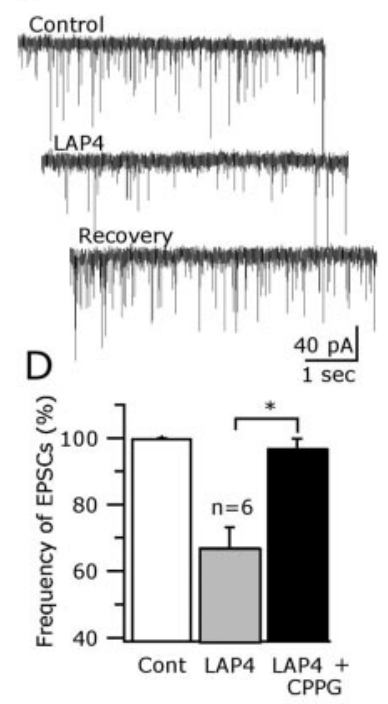

Figure 1. Group III metabotropic glutamate receptors inhibit spontaneous excitatory synaptic activity in hypocretin neurons. $A$, Time course of the inhibitory L-AP-4 $(100 \mu \mathrm{M})$ effects on the SPSCS. B, Raw traces showing the reversible effect of L-AP-4 on the postsynaptic current frequency. C, Dose-response relationships for L-AP-4 inhibition of EPSC frequency. D, Parallel experiments in the presence of $30 \mu \mathrm{MBIC}$ show a reduction of EPSCS ( $\left.{ }^{*} p<0.01 ; n=6\right)$. The group III mGluR antagonist CPPG (200 $\mu \mathrm{M})$ substantially reduced the L-AP-4-mediated inhibition of EPSC frequency $\left({ }^{*} p<0.01 ; n=6\right.$ ). Glutamate receptor antagonists ( $50 \mu \mathrm{MAP}-5$ and 10 $\mu \mathrm{M}$ (NQX) blocked the EPSCs, suggesting glutamate as the active transmitter (data not shown).

activity, we examined the effect of L-AP-4 on electrically evoked potentials under current clamp. EPSPs were evoked by stimulating within the LH with bipolar stimulation electrodes and were recorded at a membrane potential near $-65 \mathrm{mV}$, in the presence of $30 \mu \mathrm{M}$ BIC in the bath to abolish inhibitory GABA currents. Application of $100 \mu \mathrm{M} \mathrm{L}-\mathrm{AP}-4$ reduced the amplitude of the evoked EPSPs compared with the control, as shown in Figure 2, $A 1$ and $A 2$. A reduction of $55.2 \pm 9 \%$ in the amplitude of evoked responses was induced by L-AP-4 compared with the control level (range, $32.8-85.6 \% ; n=5$ ) (Fig. 2A1). This effect of L-AP-4 was reversible and statistically significant, as suggested by an ANOVA $(p<0.001)$. The evoked responses were abolished by bath application of glutamate receptor antagonists CNQX $(10 \mu \mathrm{M})$ and AP-5 (50 $\mu \mathrm{M})$, confirming that the evoked potentials were attributable to glutamate excitation of AMPA and NMDA receptors (Fig. 2 B1,B2) $(p<0.001 ; n=6$; ANOVA). Similar effects were found when the stimulating electrode was placed medial or lateral to the recorded cell.

\section{Group III mGluRs depress local excitatory inputs to hypocretin neurons}

Group III mGluRs could modulate the release of glutamate from axons arising from local glutamatergic neurons in the LH or from other glutamate cells located outside the LH synapsing on hypocretin neurons. To study these possibilities, we first evaluated the effect of L-AP-4 on EPSCs in LH microslices, a small slice of tissue in which only the LH area (medial hypothalamus was cut out) was used, as shown in Figure $3 \mathrm{~A}$. All experiments were done in the presence of $30 \mu \mathrm{M}$ BIC. Under these conditions, a large number of spontaneous EPSCs were observed in hypocretin neurons (Fig. $3 B$ ). AP-5 at $50 \mu \mathrm{M}$ and $10 \mu \mathrm{M}$ CNQX completely blocked these currents, confirming that they were attributable to the activation of NMDA- and AMPA-type glutamate receptors, respectively
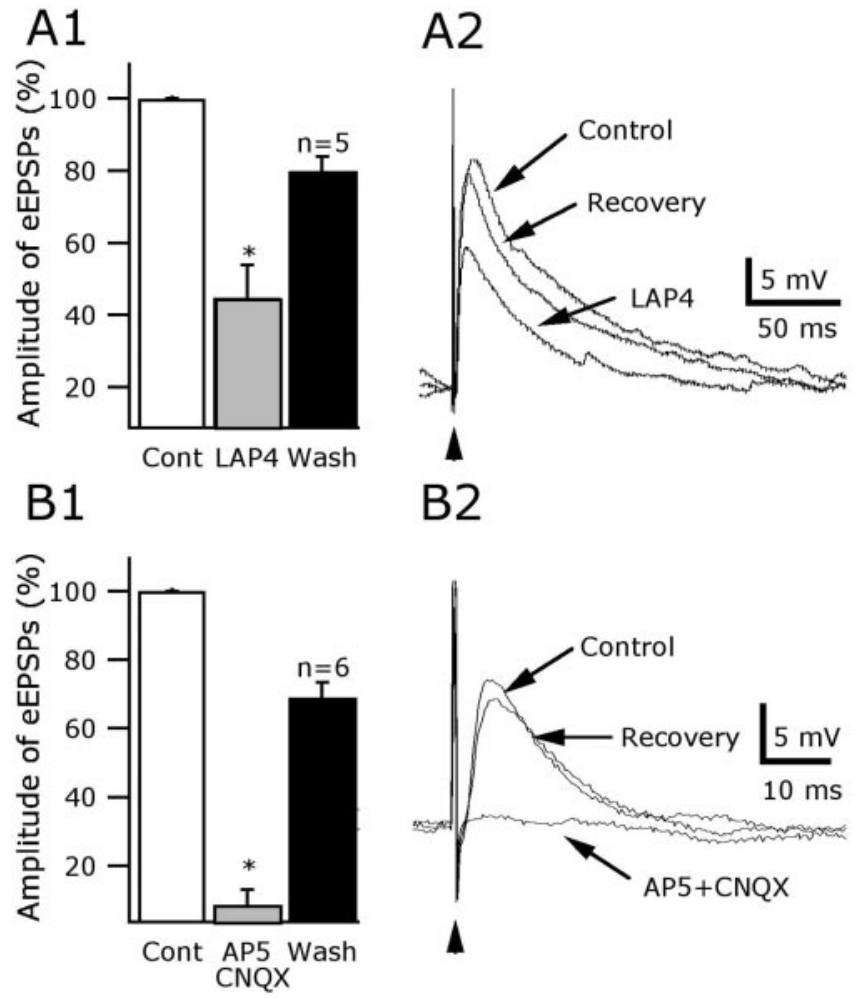

Figure 2. mGluR attenuation of evoked glutamate-mediated excitatory potentials. EPSPs were evoked by electrical stimulation (arrowhead) in the lateral hypothalamus, medial or lateral to the recorded cell. A1, The amplitude of evoked potentials was depressed by $55.2 \pm 9 \%$ (mean \pm SEM) in $100 \mu \mathrm{ML}-\mathrm{AP}-4$ and subsequently recovered ( ${ }^{*} p<0.001$ ). A2, Representative traces demonstrating the inhibitory effect of L-AP-4 (100 $\mu \mathrm{M})$ on excitatory evoked transmission in hypocretin cells. The membrane potential of the cells was held at $-65 \mathrm{mV}$. B1, B2, These evoked EPSPs were attributable to glutamate release, because they were blocked by AP-5 (50 $\mu \mathrm{M})$ and $\mathrm{CNQX}(10 \mu \mathrm{M})\left({ }^{*} p<0.001 ; n=6\right)$.

( $n=7$; data not shown). The group III mGluR agonist L-AP-4 reversibly reduced the frequency of EPSCs (Fig. $3 B$ ). The spontaneous EPSC frequency was suppressed by $30.7 \pm 5.9 \%$, recovering to $93.8 \pm 9.1 \%$ after L-AP- 4 washout, a statistically significant effect ( $n=6 ; p<0.05$; ANOVA). No change was detected in the mean amplitude of the excitatory events $(n=6 ; p=0.86$; ANOVA) or in the cumulative distributions of the amplitude after L-AP-4 ( $p>0.05 ; n=6$; Kolmogorov-Smirnov test), suggesting that the activation of group III mGluRs suppressed both large and small EPSCs.

To evaluate further the presence of local glutamatergic circuits within the LH, glutamate (5-10 mM) was microapplied $0.5-1 \mathrm{~mm}$ away from the recorded hypocretin cells. All experiments were done holding the cells at $-60 \mathrm{mV}$ under voltage clamp and in the presence of $30 \mu \mathrm{M}$ BIC to block the inhibitory synaptic transmission. When the glutamate microdrop was applied at a distance from the recorded cell, we found an increase in the fast excitatory synaptic activity with no slow inward current, suggesting that no direct activation of the somatodendritic glutamate receptors of the recorded cell was elicited by the microdrop (Fig. 3C, trace 1) $(n=4)$. In contrast, when the microdrop was directly applied to the recorded cells, a slow inward current (0.05-1 nA) was observed, followed by a late increase in the baseline noise (Fig. $3 C$, trace 4$)(n=7)$. Glutamate microapplication in the LH evoked a significant increase $(51.4 \pm 14.7 \%)$ in the frequency of excitatory synaptic activity in the 5-15 sec after the glutamate microapplication (Fig. $3 C$, trace 1$)(n=4 ; p<0.05$; ANOVA). This effect 


\section{A Lateral hypothalamic slice}
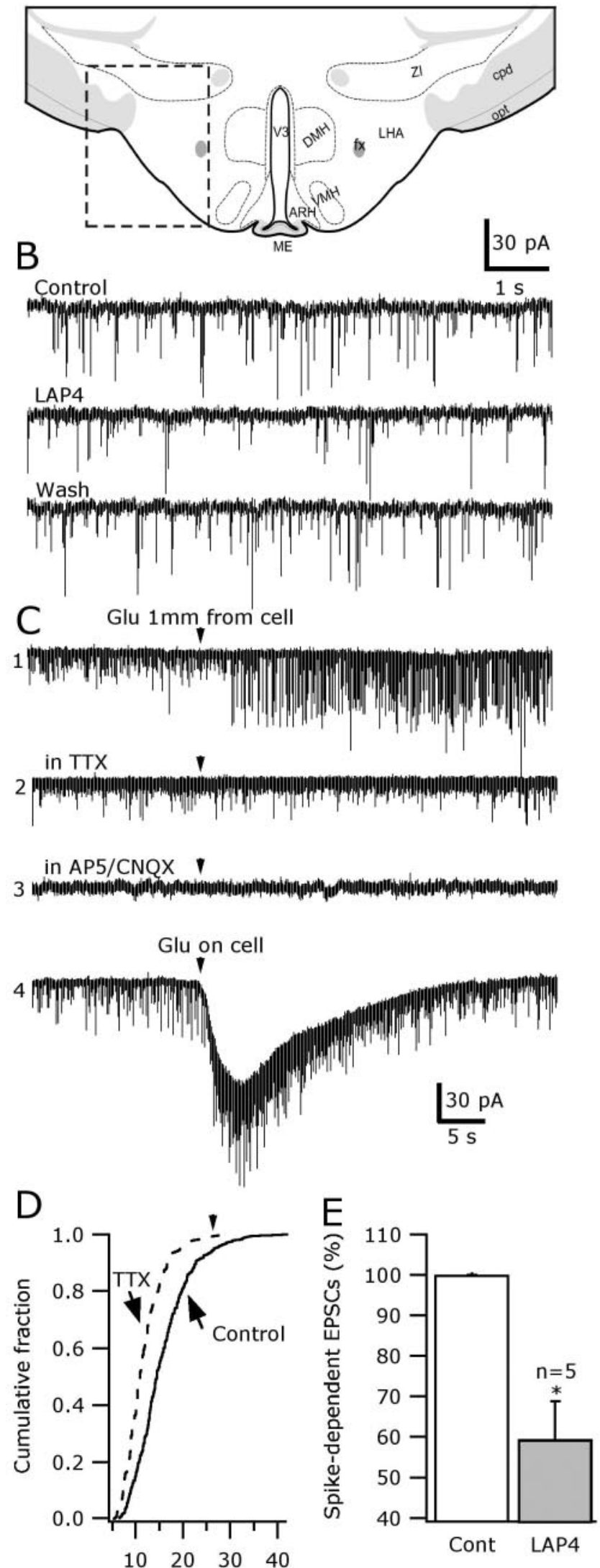

Amplitude (pA) was completely abolished with $0.5 \mu \mathrm{M}$ TTX, confirming that it was spike dependent and attributable to the activation of presynaptic excitatory interneurons innervating hypocretin cells (Fig. $3 C$, trace 2$)(n=4 ; p=0.81$; ANOVA). We also performed glutamate microdrop experiments in the presence of the ionotropic glutamate receptor antagonists. In $50 \mu \mathrm{M} \mathrm{AP}-5$ and $10 \mu \mathrm{M}$ CNQX, all of the fast excitatory synaptic activity was blocked, and the glutamate microdrop failed to increase the EPSC frequency (Fig. 3C, trace 3) $(n=5)$. Together, these experiments revealed the presence of local glutamatergic neurons within the LH that sent projections to the hypocretin cells and that were stimulated by the glutamate microdrop.

We additionally evaluated the presence of spontaneous spikedependent excitatory activity in the LH preparation by application of $0.5 \mu \mathrm{M}$ TTX to the slice. These experiments were done in the presence of $30 \mu \mathrm{M}$ BIC to suppress inhibitory transmission. In TTX, the spontaneous frequency of EPSCs was reduced by $34.6 \pm$ $5.3 \%$. This effect was statistically significant $(n=7 ; p<0.05$; ANOVA). The mean amplitude of the excitatory current was also decreased by TTX ( $n=7 ; p<0.01$; ANOVA), cumulative distributions of the amplitude were left shifted by TTX, and all of the events bigger than $28 \mathrm{pA}$ were completely abolished in all cells tested, consistent with the idea that large excitatory ( $>28 \mathrm{pA})$ currents are primarily spike dependent. This change in the cumulative distribution of the amplitude in the presence of TTX was statistically significant in all of cells tested (Fig. $3 D)(p<0.05$; Kolmogorov-Smirnov test). These results provide support for the view that local, spontaneously active, glutamate neurons innervate the hypocretin cells in the LH.

To further evaluate the effect of L-AP-4 on the spikedependent excitatory postsynaptic activity, we first quantitatively compared the effect of L-AP-4 on the excitatory currents in the presence and absence of TTX. L-AP-4 depressed by 28.1 and $32.1 \%$ the frequency of miniature and spike-dependent excitatory currents, respectively. On the basis of the result that all of the large events ( $\geq 28 \mathrm{pA})$ (Fig. $3 D$, arrowhead) were completely abolished by TTX, we selected only those events $\geq 28 \mathrm{pA}$ and compared their frequency before and during the application of L-AP-4. Under these conditions, we found that L-AP-4 significantly reduced the frequency of the large, spike-dependent EPSCs by $40.5 \pm 9.3 \%$ compared with control levels (Fig. $3 E)(p<0.05$; $n=5$; ANOVA). Additionally, we performed an analysis of those events that had an amplitude $\geq 56 \mathrm{pA}$ (twice that of the maximal amplitude found in TTX). Under these conditions, L-AP-4 depressed EPSCs by $35.9 \pm 5.03 \%$. Because all other neurons were eliminated in these microslices that were restricted to the $\mathrm{LH}$,

\section{$\leftarrow$}

Figure 3. L-AP-4 depressed local synaptic glutamate release in the lateral hypothalamus. $A$, Schematic representation of the lateral hypothalamic region dissected out to study the local excitatory inputs to hypocretin cells. ARH, Arcuate nucleus of the hypothalamus; cpd, cerebral peduncle; DMH, dorsomedial hypothalamus; fx, fornix; LHA, lateral hypothalamic area; ME, median eminence; opt, optic tract; VMH, ventromedial hypothalamus; V3, third ventricle; Zl, zona incerta. $B$, The group III mGluR agonist L-AP-4 (100 $\mu \mathrm{M})$ reversibly depressed the frequency of spontaneous EPSCs. C, Trace 1 shows the excitatory synaptic response, but not direct response, to glutamate microapplication $1 \mathrm{~mm}$ away from the recorded cell. Trace 2 shows that, in the presence of TTX, the glutamate microdrop failed to increase the EPSC frequency. Trace 3 shows the glutamate microdrop experiment after ionotropic glutamate receptors blockade. № increase in the EPSC frequency was detected. In trace 4 is shown the slow inward current evoked by glutamate directly applied to the recorded cell. D, TTX at $0.5 \mu \mathrm{m}$ changed (left shift) the cumulative fractions of the EPSC amplitude. Arrowhead shows the point at which all events in TTX can be accounted for (maximum of $27 \mathrm{pA})$. E, L-AP-4 $(100 \mu \mathrm{M})$ reduced the frequency of large spike-dependent EPSCs (amplitude, $\geq 28 \mathrm{pA}$ ) by $40.5 \pm 9.3 \%\left({ }^{*} p<0.05 ; n=5\right)$. 
together, these data support the view that group III mGluRs inhibit glutamate release from axons arising from local neurons within the LH slices that made synaptic contact with the hypocretin cells.

\section{Presynaptic effects of L-AP-4 on excitatory transmission}

Anatomical and electrophysiological studies have shown that group III mGluRs can be located presynaptically or postsynaptically on different neurons (Martin et al., 1997; Shigemoto et al., 1997; Bradley et al., 1999; Taverna and Pennartz, 2003). To examine the site of action of the metabotropic group III agonist L-AP-4 in hypocretin neurons, we further studied its effect on the amplitude and frequency of miniature EPSCs (mEPSCs). Experiments were done in the presence of $0.5 \mu \mathrm{M}$ TTX and $30 \mu \mathrm{M}$ BIC. Application of L-AP-4 resulted in a reversible decrease in $\mathrm{mEPSC}$ frequency. The traces in Figure $4 A$ provide a clear illustration of this effect in a typical neuron. L-AP-4 $(100 \mu \mathrm{M})$ decreased the mean mEPSC frequency by $37.5 \pm 7.5 \%(p<0.005 ; n=8$; ANOVA) compared with pre-L-AP- 4 control levels, returning to $103.5 \pm 11.3 \%$ after washout (Fig. $4 B$ ). No change in the event amplitude was detected when the cumulative probability distributions in control and L-AP-4 conditions were compared in five cells (Fig. $4 C$ ) ( $p>0.05$; Kolmogorov-Smirnov test), consistent with a presynaptic effect of L-AP-4.

We also evaluated the effect of L-AP- 4 on the $I-V$ relationships in current clamp with TTX $(0.5 \mu \mathrm{M})$, AP-5 (50 $\mu \mathrm{M})$, CNQX (10 $\mu \mathrm{M})$, and BIC (30 $\mu \mathrm{M})$ in the bath. Under these conditions, we did not detect any change in the $I-V$ relationships in L-AP-4 in eight of eight cells tested. A typical experiment showing the lack of L-AP-4 effect on the $I-V$ relationship is presented in Figure $4 D$. Additionally, we evaluated the L-AP-4 effect on the input resistance of hypocretin cells. To address this issue, a linear function was adjusted to the voltage responses of the hypocretin cells after brief negative current injections (from -160 to $20 \mathrm{pA}, 20 \mathrm{pA}$ steps, $300 \mathrm{msec}$ duration, $1 \mathrm{sec}$ interstimulus intervals). The mean slope of these arithmetic functions in control, L-AP-4, and wash conditions was obtained in eight cells and compared using an ANOVA. L-AP-4 had no effect; input resistance was $628.9 \pm$ $22.5,620.3 \pm 24.1$, and $626.4 \pm 24.4 \mathrm{M} \Omega$ in control, $\mathrm{L}-\mathrm{AP}-4$, and recovery conditions, respectively. This effect was not statistically significant $(p=0.86)$.

Another method of evaluating the site of action of L-AP-4 is to determine its effect on postsynaptic AMPA-evoked currents in the presence of $0.5 \mu \mathrm{M}$ TTX to block action potential-mediated synaptic activity. If the effects of L-AP-4 were mainly presynaptic, we would expect no change in the amplitude of the AMPAevoked currents. In eight cells studied, the current response of AMPA receptors to flow pipe application of AMPA $(5$ or $30 \mu \mathrm{M}$, $20 \mathrm{sec})$ was not altered by L-AP-4 (Fig. $4 E)(p=0.25 ; n=8$; ANOVA), consistent with a presynaptic action of L-AP-4.

These results are consistent with the view that L-AP-4 modulates presynaptically the excitatory synaptic input to hypocretin cells.

\section{mGluR and inhibitory transmission}

Because GABA appears to account for most inhibitory synaptic transmission in the hypothalamus (Decavel and van den Pol, 1990), we asked whether the activation of group III glutamate metabotropic receptors might modulate the activity of GABAergic inputs of hypocretin cells. To address this question, we tested the effect of L-AP-4 (100 $\mu \mathrm{M})$ on spontaneous IPSCs. AP-5 (50 $\mu \mathrm{M})$ and $\mathrm{CNQX}(10 \mu \mathrm{M})$ were bath applied, and $\mathrm{KCl}$ was used in the pipette solution. Under these conditions, IPSCs were identi- fied as inward currents at $-60 \mathrm{mV}$ holding potential (Fig. 5A). The IPSCs were completely abolished by BIC $(30 \mu \mathrm{M})$, confirming that they are attributable to GABA release $(n=7$; data not shown). In L-AP-4, a reversible decrease in the frequency of IPSCs was detected (Fig. 5A). The frequency of inhibitory activity was suppressed by $31.1 \pm 1.9 \%$, and recovery was observed after washout (Fig. 5B). This effect was statistically significant (ANOVA; $p<0.001 ; n=6$ ).

We further studied the presynaptic and/or postsynaptic effect of L-AP- 4 on inhibitory transmission. TTX $(0.5 \mu \mathrm{M})$ was added to the ACSF to study mIPSCs. The frequency of mIPSCs was decreased by L-AP-4 $(100 \mu \mathrm{M})$, with a mean reduction of $56.4 \pm$ 7.1\% (Fig. 5C,D) $(p<0.001 ; n=6$; ANOVA; maximum decrease, $78 \%$ )

We did not detect any significant effect of L-AP-4 on the mean mIPSC amplitude $(42.4 \pm 6.2,46.1 \pm 6.3$, and $45.8 \pm 7.2 \mathrm{pA}$ in control, L-AP-4, and recovery, respectively; $p>0.05 ; n=7$; ANOVA) or in the cumulative distributions of the amplitude in the seven cells tested ( $p>0.05 ; n=7$; Kolmogorov-Smirnov test). Pretreatment with $200 \mu \mathrm{M} \mathrm{CPPG}$ significantly depressed the effect of L-AP-4 on IPSCs (Fig. $5 F)(n=7$; $p<0.05$; ANOVA followed by a Bonferroni procedure for multiple comparisons). Together, these results suggest presynaptic, group III mGluRmediated, modulation of GABAergic inhibitory transmission to the hypocretin cells.

\section{Ongoing activation of group III mGluRs in hypocretin cells}

To test the hypothesis that there is an ongoing inhibitory activity of group III mGluRs on excitatory synaptic inputs of hypocretin cells, we evaluated the effect of a group III-specific antagonist CPPG on the frequency of EPSCs. BIC at $30 \mu \mathrm{M}$ was used in all experiments to block inhibitory synaptic activity. With the cell at $-60 \mathrm{mV}$ holding potential and under voltage clamp, CPPG (200 $\mu \mathrm{M})$ increased the frequency of spontaneous EPSCs, as shown in Figure 6, $A 1$ and $A 2$. In the presence of this drug, we observed an increase up to $59.6 \%$ in EPSCs (mean, $15.5 \pm 6.2 \%$ ) (Fig. 6A3). This increase was statistically significant $(p<0.05 ; n=12$; ANOVA). The frequency of the EPSCs returned to $94.6 \%$ of the control level after 5-10 min of CPPG washout.

We also tested whether group III mGluRs maintained an inhibitory tone on GABA synaptic transmission in hypocretin cells. AP-5 at $50 \mu \mathrm{M}$ and $10 \mu \mathrm{M}$ CNQX were bath applied to block the excitatory synaptic activity, and the cells were held at $-60 \mathrm{mV}$. $\mathrm{KCl}$ was used in the recording pipette to detect IPSCs. CPPG at $200 \mu \mathrm{M}$ did not increase the frequency of inhibitory currents in hypocretin neurons (Fig. 6B1,B2). The frequency of IPSCs was $98.3 \pm 3.6$ during CPPG and $101.9 \pm 6.3 \%$ after CPPG washout, respectively, compared with the control level (Fig. 6B3) $(n=8$; $p=0.84$; ANOVA).

The finding that CPPG selectively enhanced the spontaneous excitatory activity suggests that spontaneous glutamate release activates presynaptic metabotropic receptors, thereby suppressing transmitter release from glutamatergic, but not GABAergic, axon terminals on hypocretin neurons.

\section{Group III mGluRs inhibit hypocretin-evoked excitation of hypocretin neurons}

Most fast excitatory activity in the hypothalamus appears to be mediated by glutamate (van den Pol and Trombley, 1993). Recently, we suggested that hypocretin excites hypocretin neurons by activation of local glutamate interneurons in the LH ( $\mathrm{Li}$ et al., 2002). Because group III mGluRs presynaptically suppressed glutamatergic activity in the hypocretin neurons, we further hypoth- 


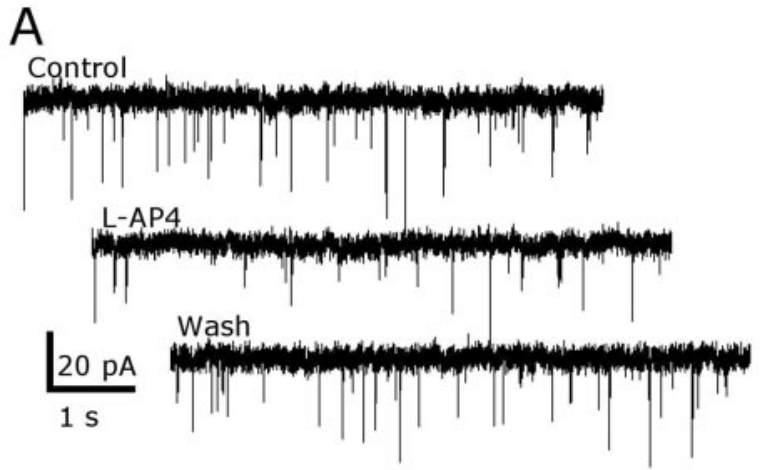

B


Figure 4. Presynaptic mechanism: group III mGluRs attenuate miniature EPSC frequency. $A$, $\mathrm{mEPSC}$ were recorded from hypocretin cells held at $-60 \mathrm{mV}$ in the presence of $0.5 \mu \mathrm{m}$ TTX. L-AP-4 (100 $\mu \mathrm{M})$ induced a reversible decrease in the frequency of mEPSCS. B, Summary bar graph of data illustrating a significant effect of L-AP-4 on the frequency (mean \pm SEM) of $\operatorname{mEPSCS}\left({ }^{*} p<0.005 ; n=8\right.$; ANOVA). C, Cumulative histogram of a typical cell showing the lack of L-AP-4 effect on mEPSC amplitude ( $p=0.71 ; n=5$; Kolmogorov-Smirnov test). $D, I-V$ relationships in a typical cell. $\mathrm{L}-\mathrm{AP}$-4 did not alter the input resistance of hypocretin cells $(n=8$; $p=0.86$; ANOVA). E, L-AP-4 did not alter the response of postsynaptic AMPA receptors, as shown in the representative traces in hypocretin neurons before (left), during (middle),

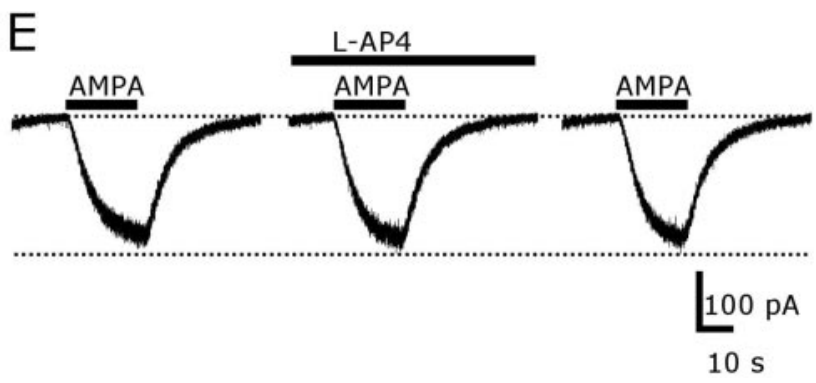

A

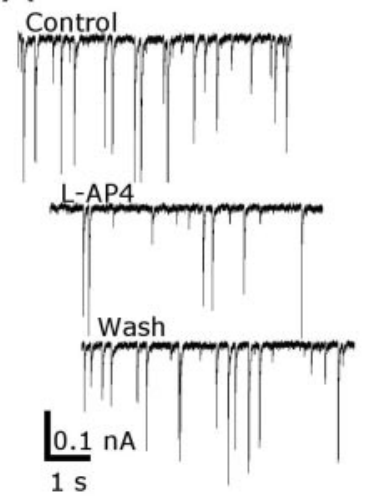

B

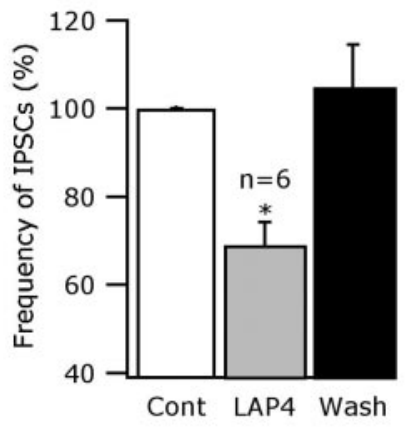

C
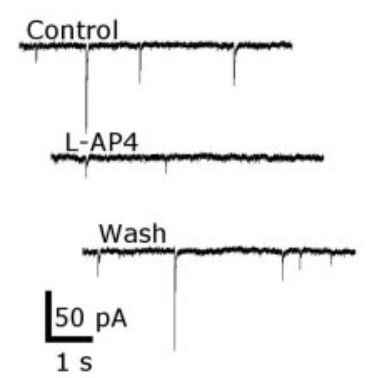

$\mathrm{E}$
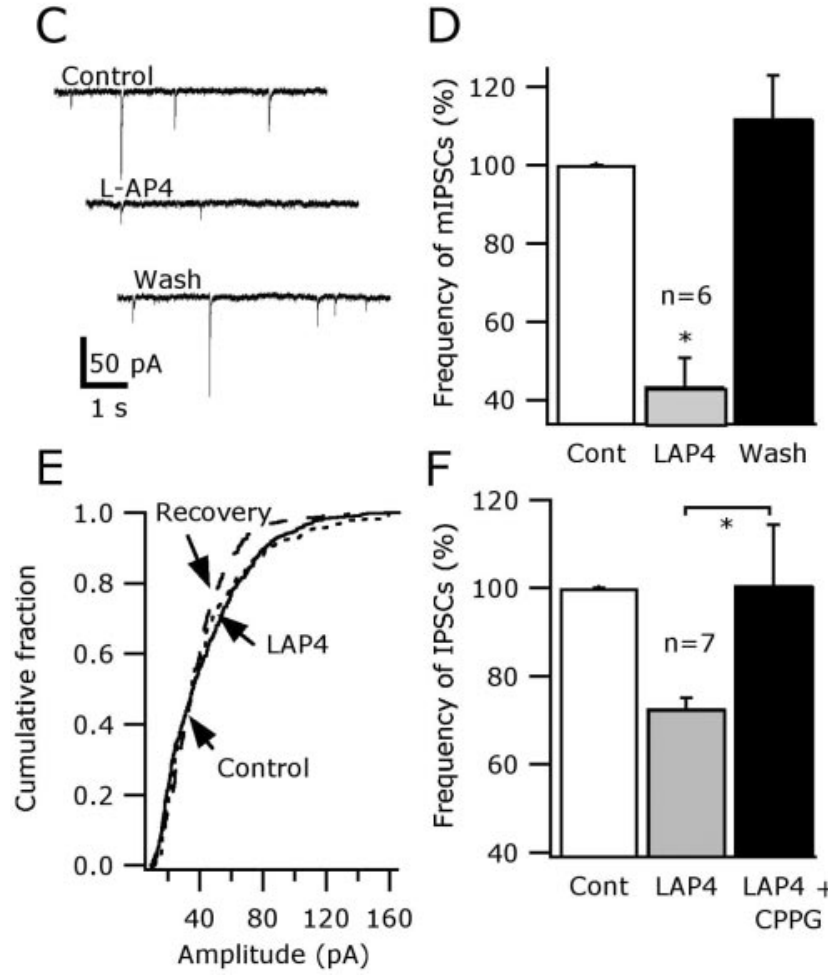

$\mathrm{F}$

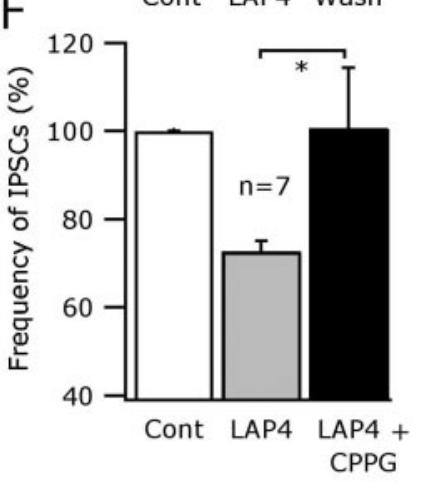

Figure 5. Presynaptic mGluR inhibition of GABA-mediated synaptic currents. A, Using whole-cell voltage clamp and the glutamate receptor antagonists AP-5 (50 $\mu \mathrm{m})$ and CNQX (10 $\mu \mathrm{M})$ in the bath and $\mathrm{KCl}$ in the pipette, spontaneous IPSCs were recorded. L-AP-4 (100 $\mu \mathrm{M})$ decreased the frequency of inhibitory currents in these typical traces. $B$, Bar graph shows the mean \pm SEM IPSC frequency before, during, and after L-AP-4 ( ${ }^{*} p<0.001 ; n=6$; ANOVA). $C$, In the presence of $0.5 \mu \mathrm{M}$ TTX in the bath, the effect of L-AP-4 on mIPSCS was examined. L-AP-4 decreased the frequency $(D)\left({ }^{*} p<0.001 ; n=6 ;\right.$ ANOVA) but did not alter the amplitude $(E)$ ( $p>0.05 ; n=7$; Kolmogorov-Smirnov test) of mIPSCs, suggesting a presynaptic effect on inhibitory transmission. $F$, Bar graph shows that, in the presence of the group III mGluR antagonist CPPG $(200 \mu \mathrm{m})$, L-AP-4 actions were suppressed.

esized that L-AP-4 may reduce the excitation induced by hypocretin on hypocretin neurons. To address this question, the effect of L-AP-4 on both hypocretin-mediated postsynaptic currents and firing rate was evaluated.

$L-A P-4$ depressed hypocretin-mediated increases in EPSCs

Using voltage clamp, EPSCs were studied at $-60 \mathrm{mV}$ holding potential. All experiments were done in the presence of $30 \mu \mathrm{M}$

$\leftarrow$

and after (right) bath application of $100 \mu \mathrm{m} \mathrm{L}-\mathrm{AP}-4$. These results support the view that L-AP-4 presynaptically modulates excitatory transmission in hypocretin cells. 


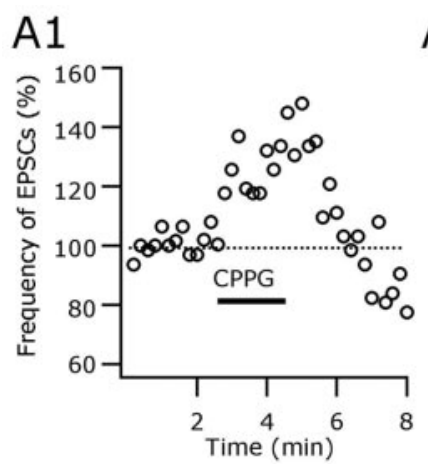

B1



B2

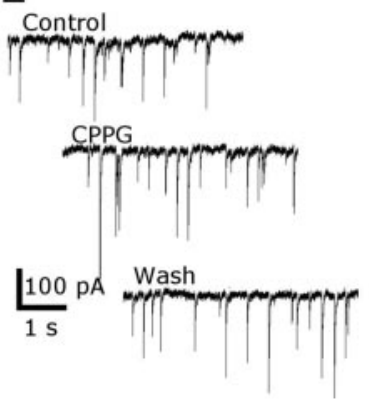

A3

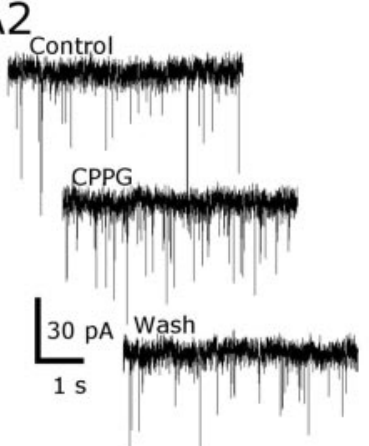

B3

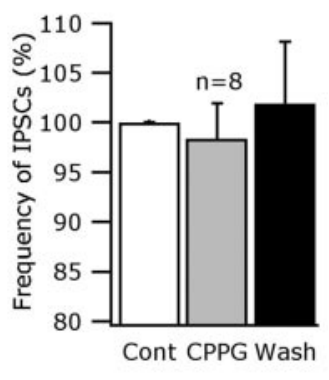

Figure 6. Normal mGluR inhibitory tone blocked by group III antagonists. A1, CPPG (200 $\mu \mathrm{m})$, a selective group III mGluR antagonist, increased the spontaneous EPSCs in hypocretin neurons. BIC at $30 \mu \mathrm{m}$ was used in all experiments. $A 2$, Representative traces showing the CPPG (200 $\mu \mathrm{m})$ effect on the frequency of the EPSCs. A3, The data from 12 neurons were combined in a bar graph. The frequency of EPSCs was increased by $15.5 \pm 6.9 \%$ (mean \pm SEM) during CPPG administration and returned to the baseline after washout. This (PPG effect on the frequency of EPSC s was statistically significant $\left({ }^{*} p<0.05 ; n=12\right) . B 1, B 2, C P P G$ $(200 \mu \mathrm{M}$ ) did not increase the frequency of the inhibitory currents in hypocretin cells (50 $\mu \mathrm{M}$ AP-5 and $10 \mu \mathrm{M}$ CNQX were bath applied in all experiments). B3, The IPSC frequency was $98.3 \pm 3.6 \%$ in CCPG compared with control levels (100\%) $(n=8 ; p=$ 0.79; ANOVA). These results suggest that group III mGluRs maintain a tonic inhibition of glutamatergic, but not GABAergic, synaptic inputs in hypocretin cells.

BIC to block GABA transmission. The control baseline was recorded for 5-10 min, and then Hcrt- 2 was applied for 2 min. Hcrt-2 $(2 \mu \mathrm{M})$ significantly increased the frequency of EPSCs by $22 \pm 6.3 \%$ compared with the control baseline and returned to basal levels $10 \mathrm{~min}$ after washout (Fig. $7 \mathrm{~A}, C)(p<0.05 ; n=5$; ANOVA). Then, $100 \mu \mathrm{M} \mathrm{L}-\mathrm{AP}-4$ was added to the bath, and the effect of Hcrt-2 was tested again in the same cell. The group III mGluR agonist decreased the frequency of spontaneous EPSCs by $38.1 \%$ (Fig. $7 C$ ). After $5 \mathrm{~min}$ of baseline recording in the presence of L-AP-4, 2 min application of Hcrt-2 did not increase the frequency of EPSCs relative to L-AP-4 levels (Fig. $7 B)(p=$ $0.82 ; n=5$; ANOVA and Bonferroni analysis for multiple comparisons). In two cells, the order of drug application was reversed, with no different effect on the outcome of the experiment. Our experiments support the view that group III mGluRs depress hypocretin-mediated increases in EPSCs.

\section{Group III mGluRs attenuated hypocretin-induced spike} frequency increase

Hypocretin enhances the firing rate of hypocretin neurons, mainly by increasing the excitatory synaptic transmission (Li et al., 2002). If the activation of group III mGluRs suppresses the effect of hypocretin on EPSCs, as shown above, suppression in the hypocretin-induced spike frequency response might be expected. To test this hypothesis, the firing rate response evoked by the application of $2 \mu \mathrm{M}$ Hcrt-2 before and after application of L-AP-4 were compared. In control conditions, Hcrt-2 induced a significant increase in the frequency of action potentials (Fig.
$7 B, D)(n=7 ; p<0.05$; ANOVA $)$. The mean firing rate was increased by $71.8 \%$ by Hcrt-2 and returned to the control baseline after washout. Then, $100 \mu \mathrm{M} \mathrm{L}-\mathrm{AP}-4$ was added to the bath, and the response to hypocretin was tested again. L-AP-4 did not affect the basal firing rate of hypocretin cells (Fig. $7 B, D)(n=7)$. The excitatory effect of hypocretin on spike frequency was suppressed in the presence of L-AP-4 (Fig. 7D). In the presence of L-AP-4, the excitatory effect of hypocretin was depressed by $43.9 \pm 7.7 \%(p<0.05$; $n=7$; ANOVA and Bonferroni post hoc test). Because these experiments were done in the absence of BIC, the data suggest that, in hypothalamic slices, activation of group III mGluRs may have a more profound effect on excitatory than inhibitory feedback to hypocretin neurons.

Together, these data show that group III metabotropic glutamate receptors modulate hypocretin-mediated excitation (both EPSCs and spike frequency) of hypocretin neurons and suggest that these receptors are expressed by axons of local hypocretin-sensitive glutamate neurons in the LH.

\section{Discussion}

In the present work, we show that activation of group III mGluRs results in a reduction of synaptic activity recorded in hypocretin neurons by a presynaptic mechanism. The increase in synaptic activity in the presence of group III mGluR antagonists suggests that these receptors may provide a tonic inhibitory tone to the synaptic input to the hypocretin neurons. Activation of these metabotropic glutamate receptors substantially attenuates the ability of hypocretin to excite hypocretin neurons by a mechanism based on reduction of glutamate release onto hypocretin neurons.

\section{Site of mGluR action}

Previous work with group III mGluRs in other regions of the brain has shown a variety of response types, including presynaptic and postsynaptic modulation leading to circuit inhibition or excitation (Semyanov and Kullmann, 2000; Awad-Granko and Conn, 2001). Neurons in some regions of the brain show group III mGluR postsynaptic modulation (Martin et al., 1997; Taverna and Pennartz, 2003). In contrast, in the present study, we found no indication of any postsynaptic response to mGluR activation, as revealed by studies of input resistance, current-voltage relationships, or postsynaptic response to ionotropic glutamate receptor agonists. Similarly, studies of group III mGluRs in some other cell types also found no detectable postsynaptic action mediated by these glutamate receptors (Schrader and Tasker, 1997; Evans et al., 2000).

Based on an analysis of miniature PSCs, in which activation of mGluRs caused a reduction in the frequency but not amplitude of both glutamate- and GABA-mediated mPSCs, our results support the view that group III mGluRs are probably located on both glutamate and GABA presynaptic axons that innervate the hypo- 
cretin neurons. This view is consistent with our studies of electrically evoked postsynaptic potentials that were decreased in amplitude by activation of mGluRs, coupled with the absence of any modulation of postsynaptic responses to ionotropic glutamate receptor agonists. That mGluRs are located on presynaptic terminals is consistent both with previous electrophysiological (Schrader and Tasker, 1997; Evans et al., 2000; Awatramani and Slaughter, 2001) and immunocytochemical (Bradley et al., 1996, 1999; Shigemoto et al., 1997) studies of other neuronal types.

In the present study, we found a selective ongoing inhibition of glutamate, but not GABA, release mediated by group III mGluRs. This tonic inhibition suggests that sufficient glutamate is available to activate the receptors on the presynaptic terminals. In other regions of the brain, some neurons expressing mGluRs have been identified in which mGluRs were tonically inactive (Bergles and Jahr, 1997; Dube and Marshall, 2000), and other neurons both within and outside the hypothalamus have been found in which group III mGluRs were in a tonically activated state in the absence of experimental stimulation (van den Pol et al., 1998b; Awatramani and Slaughter, 2001; Losonczy et al., 2003). Although these receptors may be tonically active, a number of reports have shown that these mGluRs are even more effective at inhibiting transmitter release at high levels of synaptic activity (Scanziani et al., 1997; Dube and Marshall, 2000; Awatramani and Slaughter, 2001). The response of GABAergic axons to the group III mGluR agonist, but lack of an action of the antagonist by itself, suggests that, although GABA axons appear to express metabotropic receptors, they are not normally activated under basal conditions.

\section{Role of presynaptic glutamate inhibition of excitatory input to hypocretin neurons}

The finding that axons that innervate hypocretin neurons express functional mGluRs that inhibit release of neurotransmitter raises the question as to what the general function of these receptors might be. Glutamate appears to be the primary excitatory transmitter in synaptic terminals innervating hypocretin neurons as detected by whole-cell recording, and, immunocytochemically, large numbers of axons containing vesicular glutamate transporters are found terminating on hypocretin neurons (Li et al., 2002). One possibility is that the mGluRs may act to prevent runaway excitation of the hypocretin neurons attributable to excessive glutamate stimulation. An increased glutamate release may feed back on the parent or other nearby axons and, by activating the mGluRs, reduce the amount of released glutamate. Because mGluRs act more slowly than ionotropic glutamate receptors, the activation of the mGluRs would be expected after activation of the ionotropic receptors; this would suggest that afferent glutamate input would first activate rapidly acting excitatory postsynaptic receptors and, subsequently, would inhibit further glutamate release through the mGluRs on the presynaptic terminals. Group III mGluRs may be the targets for other presyn-
B

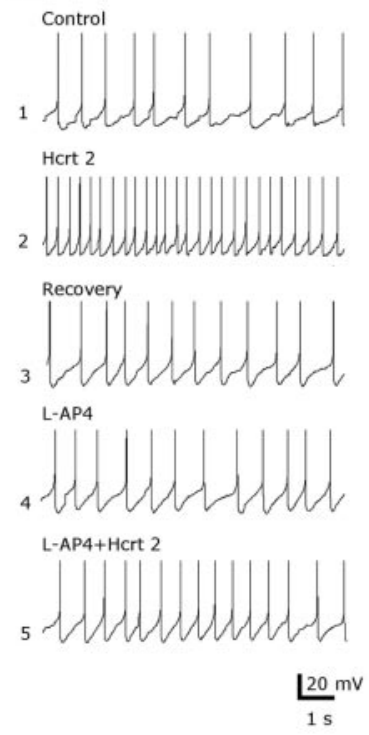

$\frac{120}{1 \mathrm{~s}} \mathrm{mV}^{2}$
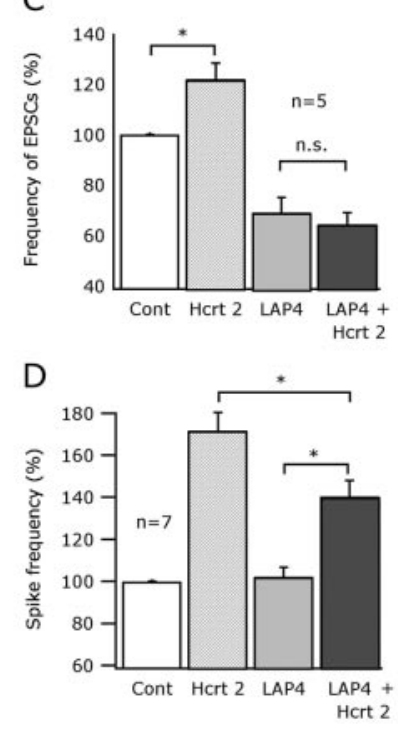

(1)

Figure 7. L-AP-4 depresses hypocretin-mediated excitation of hypocretin cells. $A, B$, Group III mGluR activation depresses the $0.05 ; n=7$; ANOVA followed by a Bonferroni comparison). n.s., Not significant.

aptic modulators. For instance, raising protein kinase $\mathrm{C}$ can attenuate the efficacy of the receptors (Macek et al., 1999), as demonstrated with norepinephrine stimulation (Gordon and Bains, 2003). Thus, other transmitters or neuromodulators related to arousal or sleep-wake cycles could shift the ongoing inhibitory actions mediated by mGluRs by presynaptic mechanisms, resulting in a selective shift in the release probability of glutamate or GABA onto hypocretin neurons. In essence, the inhibition of presynaptic release may serve to sequester hypocretin neurons from low levels of ambient synaptic activity, potentially allowing them to respond to higher levels of incoming synaptic information from other regions of the brain.

Recent work has shown that miniature PSCs, transmitter release events occurring in the absence of action potentials in the parent cell body, can modulate the firing properties of postsynaptic neurons (Kombian et al., 2000; Carter and Regehr, 2002). An increase in the firing rate of hypocretin neurons may facilitate an increase in arousal (Hagan et al., 1999), and glutamate enhances the firing rate of hypocretin neurons. This raises an interesting question of whether local spike-independent transmitter release might modulate the output of hypocretin neurons.

We find that mGluRs on axons innervating hypocretin cells reduce spike-dependent transmitter release. Together, the results suggest that at least some of the parent cell bodies of these axons are nearby the recorded cells in the same slice. This is based on the fact that large-amplitude, action potential-mediated, synaptic activity is attenuated by L-AP-4. Furthermore, activation of group III mGluRs were very effective in reducing glutamate release in minislices in which all neurons outside the $\mathrm{LH}$ were cut off before recording, consistent with the view that a substantial part of the glutamate input to hypocretin neurons may arise locally within the LH. Group III mGluRs can inhibit both GABA and glutamate release onto hypocretin neurons; in this context, the finding that 
mGluR activation results in a substantial attenuation of hypocretin-mediated excitation of hypocretin neurons suggests a stronger role for the receptor in attenuating glutamate than GABA release in the hypocretin feedback circuit. Because hypocretin cells have been postulated to express glutamate vesicular transporters and to release glutamate in addition to hypocretin (Abrahamson and Moore, 2001; Rosin et al., 2003), and given the high level of presynaptic hypocretin boutons within the LH and the apparent innervation of hypocretin neurons by other hypocretin neurons (van den Pol et al., 1998a; Horvath et al., 1999), we cannot rule out the possibility that hypocretin axons may be included in the glutamatergic axons that express functional mGluRs. Although hypocretin can exert direct excitatory actions, an additional mechanism of excitation is a hypocretin-mediated enhancement of glutamate release. This has been reported in a number of brain regions, including the hypothalamus, dorsolateral tegmentum, medial and lateral hypothalamus, and trigeminal motor nucleus (van den Pol et al., 1998a; Burlet et al., 2002; Li et al., 2002; Peever et al., 2003). In that context, the possibility that group III mGluRs not only reduce glutamate release onto hypocretin neurons but also at other sites of hypocretin action merits additional exploration.

\section{References}

Abrahamson EE, Moore RY (2001) The posterior hypothalamic area: chemoarchitecture and afferent connections. Brain Res 889:1-22.

Awad-Granko H, Conn PJ (2001) Activation of groups I or III metabotropic glutamate receptors inhibits excitatory transmission in the rat subthalamic nucleus. Neuropharmacology 41:32-34.

Awatramani GB, Slaughter MM (2001) Intensity-dependent, rapid activation of presynaptic metabotropic glutamate receptors at a central synapse. J Neurosci 21:741-749.

Belousov AB, van den Pol AN (1997) Local synaptic release of glutamate from neurons in the rat hypothalamic arcuate nucleus. J Physiol (Lond) 499:747-761.

Bergles DE, Jahr CE (1997) Synaptic activation of glutamate transporters in hippocampal astrocytes. Neuron 19:1297-1308.

Bradley SR, Levey AI, Hersch SM, Conn PJ (1996) Immunocytochemical localization of group III metabotropic glutamate receptors in the hippocampus with subtypes-specific antibodies. J Neurosci 16:2044-2056.

Bradley SR, Rees HD, Yi H, Levey AI, Conn PJ (1998) Distribution and developmental regulation of metabotropic glutamate receptor $7 \mathrm{a}$ in the rat brain. J Neurochem 71:636-645.

Bradley SR, Standaert DG, Rhodes KJ, Rees HD, Testa CM, Levey AI, Conn PJ (1999) Immunocytochemical localization of subtype 4a metabotropic glutamate receptors in the rat and mouse basal ganglia. J Comp Neurol 407:33-46.

Burlet S, Tyler CJ, Leonard CS (2002) Direct and indirect excitation of laterodorsal tegmental neurons by hypocretin/orexin peptides: implications for wakefulness and narcolepsy. J Neurosci 22:2862-2872.

Carter AG, Regehr WG (2002) Quantal events shape cerebellar interneuron firing. Nat Neurosci 5:1309-1318.

Cartmell J, Schoepp DD (2000) Regulation of neurotransmitter release by metabotropic glutamate receptors. J Neurochem 75:889-907.

Chemelli RM, Willie JT, Sinton CM, Elmquist JK, Scammell T, Lee C, Richardson JA, Williams SC, Xiong Y, Kisanuki Y, Fitch TE, Nakazato M, Hammer RE, Saper CB, Yanagisawa M (1999) Narcolepsy in orexin knockout mice: molecular genetics of sleep regulation. Cell 98:437-451.

Chen G, van den Pol AN (1998) Coexpression of multiple metabotropic glutamate receptors in axon terminals of single suprachiasmatic nucleus neurons. J Neurophysiol 80:1932-1938.

Daftary SS, Boudaba C, Szabo K, Tasker JG (1998) Noradrenergic excitation of magnocellular neurons in the rat hypothalamic paraventricular nucleus via intranuclear glutamatergic circuits. J Neurosci 18:10619-10628.

Decavel C, van den Pol AN (1990) GABA: a dominant neurotransmitter in the hypothalamus. J Comp Neurol 302:1019-1037.

Dube GR, Marshall KC (2000) Activity-dependent activation of presynaptic metabotropic glutamate receptors in locus coeruleus. J Neurophysiol 83:1141-1149.
Eriksson KS, Sergeeva O, Brown RE, Haas HL (2001) Orexin/hypocretin excites the histaminergic neurons of the tuberomammillary nucleus. J Neurosci 21:9273-9279.

Evans DI, Jones RSG, Woodhall G (2000) Activation of presynaptic group III metabotropic receptors enhances glutamate release in rat entorhinal cortex. J Neurophysiol 83:2519-2525.

Ghosh PK, Baskaran N, van den Pol AN (1997) Developmentally regulated gene expression of all eight metabotropic glutamate receptors in hypothalamic suprachiasmatic and arcuate nuclei-a PCR analysis. Brain Res Dev Brain Res 102:1-12.

Gordon GRJ, Bains JS (2003) Priming of excitatory synapses by alpha-1 adrenoreceptor-mediated inhibition of group III metabotropic glutamate receptors. J Neurosci 23:6223-6231.

Hagan JJ, Leslie RA, Patel S, Evans ML, Wattam TA, Holmes S, Benham CD, Taylor SG, Routledge C, Hemmati P, Munton RP, Ashmeade TE, Shah AS, Hatcher JP, Hatcher PD, Jones DN, Smith MI, Piper DC, Hunter AJ, Porter RA, et al. (1999) Orexin A activates locus coeruleus cell firing and increases arousal in the rat. Proc Natl Acad Sci USA 96:10911-10926.

Horvath TL, Peyron C, Diano S, Ivanov A, Aston-Jones G, Kilduff TS, van den Pol AN (1999) Hypocretin (orexin) activation and synaptic innervation of the locus coeruleus noradrenergic system. J Comp Neurol 415:145-159.

Kombian SB, Hirasawa M, Mouginot D, Chen X, Pittman QJ (2000) Shortterm potentiation of miniature excitatory synaptic currents causes excitation of supraoptic neurons. J Neurophysiol 83:2542-2553.

Li Y, Gao XB, Sakurai T, van den Pol AN (2002) Hypocretin/orexin excites hypocretin neurons via a local glutamate neuron-a potential mechanism for orchestrating the hypothalamic arousal system. Neuron 36:1-20.

Lin L, FaracoJ, Li H, Kadotani R, Rogers W, Lin X, Qui X, de Jong PJ, Nishino S, Mignot E (1999) The sleep disorder canine narcolepsy is caused by a mutation in the hypocretin (orexin) receptor 2 gene. Cell 98:365-376.

Liu RJ, van den Pol AN, Aghajanian GK (2002) Hypocretins (orexins) regulate serotonin neurons in the dorsal raphe nucleus by excitatory direct and inhibitory indirect actions. J Neurosci 22:9453-9464.

Losonczy A, Somogy P, Nusser Z (2003) Reduction of excitatory responses by persistently active metabotropic glutamate receptors in the hippocampus. J Neurophysiol 89:1910-1919.

Macek TA, Schaffhauser H, Conn PJ (1999) Activation of PKC disrupts presynaptic inhibition by group II and group III metabotropic glutamate receptors and uncouples the receptor from GTP-binding proteins. Ann NY Acad Sci 868:554-557.

Martin G, Nie Z, Siggins GR (1997) Metabotropic glutamate receptors regulate $N$-methyl-D-aspartate-mediated synaptic transmission in nucleus accumbens. J Neurophysiol 78:3028-3038.

Meeker RB, Greenwood RS, Hayward JN (1994) Glutamate receptors in the rat hypothalamus and pituitary. Endocrinology 134:621-629.

Nakanishi S (1994) Metabotropic glutamate receptors: synaptic transmission, modulation, and plasticity. Neuron 13:1031-1037.

Nishino S, Ripley B, Overeem S, Lammers GJ, Mignot E (2000) Hypocretin (orexin) deficiency in human narcolepsy. Lancet 355:39-40.

Peever JH, Lai YY, Siegel JM (2003) Excitatory effects of hypocretin-1 (orexin-A) in the trigeminal motor nucleus are reversed by NMDA antagonism. J Neurophysiol 89:2591-2600.

Peyron C, Tighe DK, van den Pol AN, de Lecea L, Heller HC, Sutcliffe JG, Kilduff TS (1998) Neurons containing hypocretin (orexin) project to multiple neuronal systems. J Neurosci 18:9996-10015.

Peyron C, Faraco J, Rogers W, Ripley B, Overeem S, Charnay Y, Nevsimalova S, Aldrich M, Reynolds D, Albin R, Li R, Hungs M, Pedrazzoli M, Padigaru M, Kucherlapati M, Fan J, Maki R, Lammers GJ, Bouras C, Kucherlapati R, et al. (2000) A mutation in a case of early onset narcolepsy and a generalized absence of hypocretin peptides in human narcoleptic brains. Nat Med 6:991-997.

Rosin DL, Weston MC, Sevigny CP, Stornetta RI, Guyenet PG (2003) Hypothalamic orexin (hypocretin) neurons express vesicular glutamate transporters VGLUT1 or VGLUT2. J Comp Neurol 465:593-603.

Scanziani M, Salin PA, Voght KE, Malenka RC, Nicoll RA (1997) Usedependent increases in glutamate concentrations activate presynaptic metabotropic glutamate receptors. Nature 385:630-634.

Schoepp DD (2001) Unveiling the functions of presynaptic metabotropic glutamate receptors in the central nervous system. J Pharmacol Exp Ther 299:12-20.

Schrader LA, Tasker JG (1997) Presynaptic modulation of metabotropic 
glutamamte receptors of excitatory and inhibitory synaptic inputs to hypothalamic magnocellular neurons. J Neurophysiol 77:527-536.

Semyanov A, Kullmann DM (2000) Modulation of GABAergic signaling among interneurons by metabotropic glutamate receptors. Neuron 25:663-672.

Shigemoto R, Kinoshita A, Wada E, Nomura S, Ohishi H, Takada M, Flor PJ, Neki A, Abe T, Nakanishi S, Mizuno N (1997) Differential presynaptic localization of metabotropic glutamate receptor subtypes in the rat hippocampus. J Neurosci 17:7503-7522.

Smith BN, Dudek ED (2001) Network interactions mediated by new excitatory connections between CA1 pyramidal cells in rats with kainateinduced epilepsy. J Neurophysiol 87:1655-1658.

Taverna S, Pennartz CM (2003) Postsynaptic modulation of AMPA- and NMDA-receptors in rat nucleus accumbens. Brain Res 976:60-68.

Thannickal TC, Moore RY, Nienhuis R, Ramanathan L, Gulyany S, Aldrich M, Cornford M, Siegel JM (2000) Reduced number of hypocretin neurons in human narcolepsy. Neuron 27:469-474.

Toms NJ, Jane DE, Kemp MC, Bedingfield JS, Roberts PJ (1996) The effects of $(R S)$-alpha-cyclopropyl-4-phosphonophenylglycine ((RS)-CPPG), a potent and selective metabotropic glutamate receptor antagonist. Br J Pharmacol 119:851-854.

Valenti O, Marino MJ, Wittmann M, Lis E, DiLella AG, Kinney GG, Conn JP (2003) Group III metabotropic glutamate receptor-mediated modulation of the striatopallidal synapse. J Neurosci 23:7218-7226.

van den Pol AN, Trombley PQ (1993) Glutamate neurons in hypothalamus regulate excitatory transmission. J Neurosci 13:2829-2836.

van den Pol AN, Gao XB, Obrietan K, Kilduff TS, Belousov AB (1998a) Presynaptic and postsynaptic actions and modulation of neuroendocrine neurons by a new hypothalamic peptide, hypocretin/orexin. J Neurosci 18:7962-7971.

van den Pol AN, Gao XB, Patrylo PR, Gosh PK, Obrietan K (1998b) Glutamate inhibits GABA excitatory activity in developing neurons. J Neurosci 18:10749-10761.

Yamanaka A, Beuckmann CT, Willie JT, Hara J, Tsujino N, Mieda M, Tominaga M, Yagami K, Sugiyama F, Goto K, Yanagisawa M, Sakurai T (2003) Hypothalamic orexin neurns regulate arousal according to energy balance in mice. Neuron 38:701-710. 